\title{
TO EVALUATE EFFICACY AND SAFETY OF RUPATADINE, BILASTINE, AND LEVOCETRIZINE IN ALLERGIC RHINITIS AT TERITARY CARE HOSPITAL, TELANGANA
}

\author{
NAGUR SHARONE GRACE ${ }^{1}$, SYED ARSHADDUDDIN AHMED ${ }^{1 *}$, BHUVANESWARI ${ }^{2}$, SYED HAMZA QUADRI ${ }^{3}$, \\ VEENA B ${ }^{1}$, MONICA ${ }^{1}$, VALISHETTI MANOJ KUMAR ${ }^{1}$
}

\begin{abstract}
${ }^{1}$ Department of Pharmacology, Osmania Medical College, Hyderabad, Telangana, India. ${ }^{2}$ Department of Pharmacology, Gandhi Medical College, Hyderabad, Telangana, India. ${ }^{3}$ Department of Pharmacology, Shadan Institute of Medical Sciences, Hyderabad, Telangana, India. Email: drarshadomc@gmail.com
\end{abstract}

Received: 18 October 2021, Revised and Accepted: 25 November 2021

ABSTRACT

Objective: Allergic rhinitis (AR) is a heterogeneous disorder characterized by symptoms - sneezing, itching, nasal congestion, and rhinorrhea. The aim of the study is to evaluate the efficacy and safety of rupatadine, bilastine, and levocetirizine in AR.

Methods: A prospective, open-label, comparative study was conducted at the Government ENT Hospital, Hyderabad, Telangana. Ninety patients diagnosed with AR were randomized, of whom Group 1 received oral tab. bilastine 20 mg once daily, Group 2 received oral tab. levocetirizine 5 mg once daily, and Group 3 received oral tab. rupatadine with a dose of $10 \mathrm{mg}$ once daily for 2 weeks. The reduction in total nasal symptom score (TNSS) and absolute eosinophil counts (AECs) was compared with baseline and at 2 weeks. Safety was assessed according to adverse events reported during the study period. An analysis of variance was used as a test of significance for the three groups.

Results: Overall, 90 cases were included in the study, with $48 \%$ of males and $52 \%$ of females. All three drugs significantly reduced the TNSS and AEC after treatment compared to before treatment $(p<0.05)$. The mean difference in TNSS and AEC showed no statistically significant difference among the three groups (TNSS: $p>0.908$ and AEC: $p>0.967$ ). In terms of safety, all three drugs showed nearly similar adverse events.

Conclusion: In this study, after 2 weeks of follow-up, the three drugs (bilastine, levocetirizine, and rupatadine) showed significant improvement clinically, but the mean reduction in the score of symptoms and AEC was not statistically significant in the treatment of AR.

Keywords: Allergic rhinitis, Bilastine, Levocetirizine, Rupatadine, Total nasal symptom score, Absolute eosinophil counts.

(c) 2021 The Authors. Published by Innovare Academic Sciences Pvt Ltd. This is an open access article under the CC BY license (http://creativecommons.org/ licenses/by/4.0/) DOI: http://dx.doi.org/10.22159/ajpcr.2021v14i12.43427. Journal homepage: https://innovareacademics.in/journals/index.php/ajpcr

\section{INTRODUCTION}

Allergy is an immune-mediated inflammatory response to common environmental allergens that are otherwise harmless [1]. The harmless substance is called an "allergen." Clemens Peter Freiherr von Pirquet, an Austrian, and Bela Schick, a Hungarian, are the two pediatricians, coined the term "allergy" from the Greek words allos, meaning "other" and ergon, meaning "reaction" to describe hypersensitivity reactions [2]. Allergic diseases include asthma, rhinitis, anaphylaxis, food, drug, or insect allergies. The burden of allergic rhinitis (AR) is immense, accounting for $55 \%$ of all allergies. AR affects between $20 \%$ and $30 \%$ of all adults [3]

\section{Classification}

Allergic and non-allergic are the two main categories of rhinitis. Seasonal AR (SAR) is traditionally caused by outdoor allergens such as pollen from trees, grass, and weeds. Perennial AR (PAR) patients exhibit symptoms year-round and are generally triggered by indoor allergens such as pets, dust mite hair, clothing, or pet dander [4].

A major change was the introduction of the terms based on the second criterion, that is, duration, AR is classified into intermittent (INT) and persistent (PER) types. AR lasting fewer than 4 days/week or less than a month per year is referred to as INT AR, and PER AR is the presence of symptoms for $\geq 4$ days/week and $\geq 1$ month/year [5].

The treatment regimen for AR includes education of patients, allergen and irritant avoidance, pharmacotherapy (all therapeutic options), and allergen immunotherapy. Central nervous system (CNS) and anticholinergic side effects are associated with the $1^{\text {st }}$ generation antihistamines (AHs). In the 1980s, upgraded new-generation AHs in terms of safety and efficacy came into the market. For mild SAR and PAR, the $2^{\text {nd }}$ generation oral AHs are considered first-line treatments [6]. This study is intended to compare the efficacy and safety of three $2^{\text {nd }}$ generation $\mathrm{AH}$ drugs, bilastine, levocetirizine, and rupatadine, in AR.

For the treatment of AR, bilastine, a new $2^{\text {nd }}$ generation $\mathrm{AH}$ that is potent and highly selective for $\mathrm{H} 1$ receptors, has been approved. It was first approved in the European Union in 2010 and is now available in many countries [6]. Bilastine has a good number of the specified attributes and meets the criteria for the treatment of AR [7]. Levocetirizine is a selective $\mathrm{H}-1$ antagonist and is the R-enantiomer of cetirizine, a potent, consistent, and long-lasting medication for the treatment of both INT and PER AR, and treatment with levocetirizine $5 \mathrm{mg}$ daily showed a significant decrease in symptoms of AR [8].

Rupatadine is a $2^{\text {nd }}$ generation $\mathrm{AH}$ against the $\mathrm{H} 1$ receptor and also has PAF antagonistic activity. Rupatadine has a fast onset of action and an increased duration of activation that helped in the improvement of symptoms and quality of life $(\mathrm{QoL})$ in patients with AR. Based on its anti-inflammatory effect, it improves nasal obstruction, which is most disturbing [9]

\section{METHODS}

The Institutional Ethics Committee approval was taken. Patients with signs and symptoms of AR participated in a randomized, open-labeled, prospective, parallel-group study, conducted in the allergy clinic of Government E.N.T. Hospital, Koti, Hyderabad, for a duration of 6 months from October 2020 to March 2021. The study was registered under 
Reg. No. ECR/300/Inst/AP/2013/RR-19. The study procedure was explained to the participants in their regional language, and written informed consent was obtained before the inclusion. If the patient is illiterate, a left thumb impression is taken. The diagnosed AR patients were screened based on inclusion and exclusion criteria.

\section{Inclusion criteria}

1. Age range: $18-55$ years

2. Both male and female patients

3. The patient was diagnosed with AR

4. Patients with symptoms for at least 1 month or more clinically

5. Patients willing to give his/her informed consent.

Exclusion criteria

1. $>50$ years old and over the age of 18

2. Patients with other systemic diseases (cardiac, hepatic, renal failure, etc.)

3. Patients with a history of physical findings of nasal pathology

4. Patients with a known history of allergy to study medication

5. Patients who are severely immunocompromised

6. Patients who are on concomitant medications (macrolides, antifungals, and steroids), pregnant and lactating women

7. Non-compliant patients.

Amid screening of 100 patients, 90 were enrolled in the study during their initial hospital visit and were randomized in a 1:1:1 allocation by the simple randomization (odd/even number) method. Each subject who fits into the criteria is allocated any one of the study drugs based on simple randomization with no masking and grouped into three groups each with 30 subjects. The sample size was calculated with standard deviation (SD) taken from the previous studies with power as $80 \%$ and level of significance as 0.05 .

\section{Treatment plan}

Thirty subjects with AR were divided into three groups: A, B, and C, received oral tab. bilastine $20 \mathrm{mg}$, oral tab. levocetirizine $5 \mathrm{mg}$, and oral tab. rupatadine $10 \mathrm{mg}$ once daily for 2 weeks. The patients were advised to take the drugs at the same time every day, $2 \mathrm{~h}$ after food at bedtime. Medical assessment of each patient was done at baseline and 2 weeks after treatment based on total nasal symptom score (TNSS) and absolute eosinophil count (AEC) levels. The TNSS [10], which includes nasal congestion, runny nose, nasal itching, and sneezing, was assessed by interviewing the patients and graded according to severity.

- Grade 0: None - no symptoms

- Grade 1: Mild - symptom clearly present but easily tolerated

- Grade 2: Moderate - symptom bothersome but tolerable

- Grade 3: Severe-symptoms that are difficult to tolerate and interfere with activity.

By adding each point of nasal symptoms, the total score of TNSS is obtained. The AR is graded depending on the severity and total score as mild $<6$, moderate $6-9$, and severe 10-12. The efficacy/treatment response was obtained by comparing the investigations and TNSS from baseline and at the end of 2 weeks among the three groups. Improvement in the scores was considered significant. Clinical safety was monitored for treatment-related adverse effects.

The observations and results were tabulated accordingly, and the data were analyzed using the Software Package for the Social Sciences. Statistical significance among three drugs was evaluated using analysis of variance. $p \leq 0.05$ was considered statistically significant.

\section{RESULTS}

The study comprised a total of 90 AR cases from the allergy clinic of the Government ENT Hospital, Hyderabad. Groups A, B, and C treated with drugs bilastine, levocetirizine, and rupatadine are given. There are no drop-outs and no loss of follow-ups.
The demographic data and clinical profile among the three groups are tabulated and compared. Among 90, males were 47 and females were 43, as shown in Fig. 1 and Table 1. The patients' age ranges from 18 to 55 years, as shown in Fig. 2 and Table 2.

In all the three groups, mean TNSS scores reduced significantly after treatment compared to before treatment $(\mathrm{p}<0.05 ; \mathrm{S})$. The decrease in

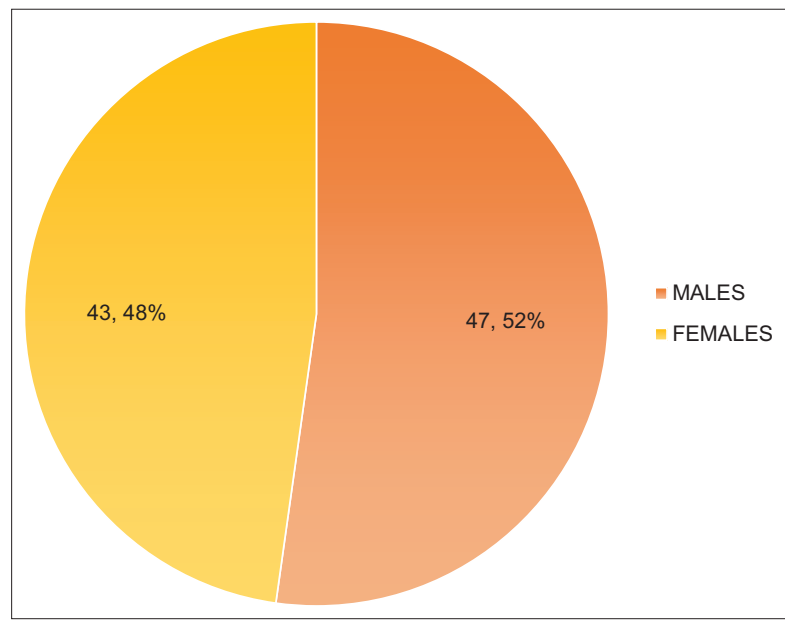

Fig. 1: Gender distribution

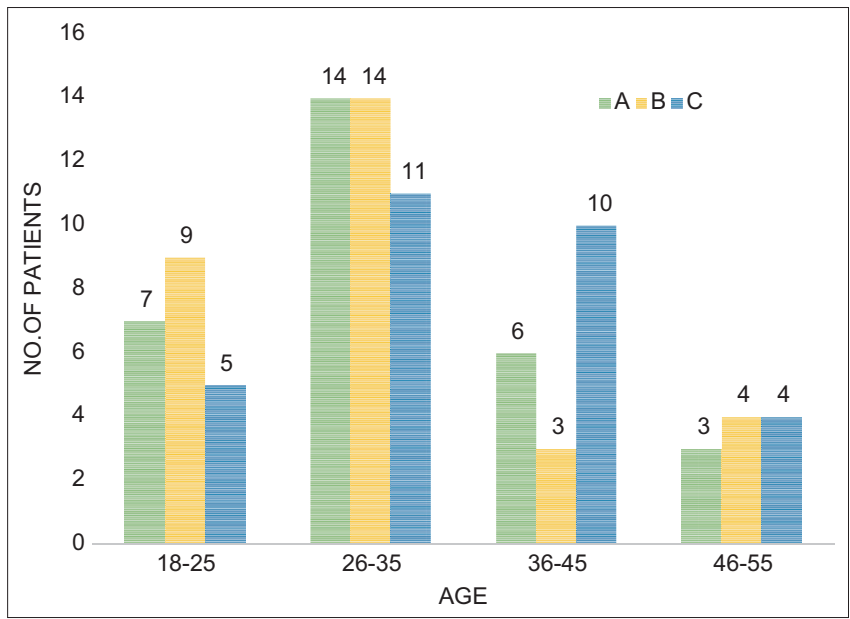

Fig. 2: Age distribution of patients among three groups

Table 1: Gender distribution of patients among three groups

\begin{tabular}{lll}
\hline Groups & Males & Females \\
\hline Group A & 16 & 14 \\
Group B & 15 & 15 \\
Group C & 16 & 14 \\
& 47 & 43 \\
\hline
\end{tabular}

Table 2: Age distribution of patients among three groups

\begin{tabular}{|c|c|c|c|c|c|c|}
\hline \multirow[t]{2}{*}{ Age } & A & \multirow[t]{2}{*}{$\%$} & B & \multirow[t]{2}{*}{$\%$} & C & \multirow[t]{2}{*}{$\%$} \\
\hline & $\begin{array}{l}\text { No. of } \\
\text { patients }\end{array}$ & & $\begin{array}{l}\text { No. of } \\
\text { patients }\end{array}$ & & $\begin{array}{l}\text { No. of } \\
\text { patients }\end{array}$ & \\
\hline $18-25$ & 7 & 23.33 & 9 & 30.00 & 5 & 16.67 \\
\hline $26-35$ & 14 & 46.67 & 14 & 46.67 & 11 & 36.67 \\
\hline $36-45$ & 6 & 20.00 & 3 & 10.00 & 10 & 33.33 \\
\hline \multirow[t]{2}{*}{$46-55$} & 3 & 10.00 & 4 & 13.33 & 4 & 13.33 \\
\hline & 30 & & 30 & & 30 & \\
\hline
\end{tabular}


Table 3: TNSS

\begin{tabular}{|c|c|c|c|c|c|c|c|c|}
\hline \multirow[t]{2}{*}{ Groups } & \multicolumn{2}{|c|}{ Pre-treatment } & \multicolumn{2}{|c|}{ Post-treatment } & \multicolumn{2}{|c|}{$\begin{array}{l}\text { Difference in pre- and } \\
\text { post-treatment }\end{array}$} & \multicolumn{2}{|c|}{ Difference between the groups } \\
\hline & Mean & SD & Mean & SD & $95 \%$ CI & p-value & ANOVA value & p-value \\
\hline Group 2 & 9.37 & 1.81 & 1.63 & 1.33 & $7.05-8.41$ & $<0.001 ; \mathrm{S}$ & & \\
\hline Group 3 & 9.30 & 1.78 & 1.53 & 1.41 & $7.00-8.53$ & $<0.001 ; \mathrm{S}$ & & \\
\hline
\end{tabular}

SD: Standard deviation, CI: Confidence interval, S: Significant, NS: Not significant, TNSS: Total nasal symptom score, ANOVA: Analysis of variance

Table 4: AECs

\begin{tabular}{|c|c|c|c|c|c|c|c|c|}
\hline \multirow[t]{2}{*}{ Groups } & \multicolumn{2}{|c|}{ Pre-treatment } & \multicolumn{2}{|c|}{ Post-treatment } & \multicolumn{2}{|c|}{$\begin{array}{l}\text { Difference in pre- and } \\
\text { post-treatment }\end{array}$} & \multicolumn{2}{|c|}{$\begin{array}{l}\text { Difference between the } \\
\text { groups }\end{array}$} \\
\hline & Mean & SD & Mean & SD & $95 \% \mathrm{CI}$ & p-value & ANOVA value & p-value \\
\hline Group 2 & 609.1 & 436.4 & 571.0 & 411.0 & $23.68-52.65$ & $<0.001 ; \mathrm{S}$ & & \\
\hline Group 3 & 554.8 & 382.3 & 519.6 & 350.4 & $19.83-50.57$ & $<0.001 ; \mathrm{S}$ & & \\
\hline
\end{tabular}

SD: Standard deviation, CI: Confidence interval, S: Significant, NS: Not significant, AECs: Absolute eosinophil counts, ANOVA: Analysis of variance

the TNSS scores is uniform in all the three groups so that there was no significant difference in TNSS scores between the groups ( $p>0.05$; NS), as shown in Table 3 . In all three groups, mean AEC reduced significantly after treatment compared to the before treatment $(\mathrm{p}<0.05 ; \mathrm{S})$. The decrease in the AEC is uniform in all three groups so that there was no significant difference in AEC between the groups ( $p>0.05 ; \mathrm{NS})$, as shown in Table 4.

There were no serious adverse events reported in the three groups. Mild adverse effects such as dryness of mouth, drowsiness, headache, vomiting, and nausea were reported in all the groups and did not require hospitalization, dose reduction, or withdrawal of treatment.

\section{DISCUSSION}

AR affects $10-40 \%$ of individuals worldwide, and it has a substantial negative effect on patients' QoL, sleep, and daily activities. For the treatment of patients with AR, fast-acting, effective, non-sedating, and modern second-generation oral H1AHs may help subside symptoms [11].

In the present study, three $2^{\text {nd }}$ generation AHs (bilastine, levocetirizine, and rupatadine) in AR were compared. As India is a developing country with variable income status and people oblivious to purchasing treatment medications, the three drugs mentioned in the study, which are readily available over the counter, need to be evaluated in terms of efficacy and safety. The European Academy of Allergy and Clinical Immunology/Allergic Rhinitis and its Impact of Asthma guidelines have defined the features that an ideal oral H1 AH should hold. Bilastine demonstrates $\mathrm{AH}$ and antiallergic properties [12]. A study found that rupatadine was better when compared to levocetirizine in the reduction of mean TNSS, immunoglobulin E, and AEC [13] and placebo [14]. Another study found significant improvement in nasal symptoms with bilastine as compared to placebo $[15,16]$. One clinical trial designed to evaluate the efficacy of levocetirizine $5 \mathrm{mg}$ once daily compared with placebo demonstrated a greater decrease in TNSS [17]. Bilastine was as effective as desloratadine [18] and cetirizine [15] in controlling AR symptoms. In patients with $\mathrm{AR}$, levocetirizine proved to have a more protective effect when compared to desloratadine and fexofenadine [8]. There are numerous studies on AHs in comparison with placebo and other $2^{\text {nd }}$ generation AHs, but there are only a few studies in comparison of three drugs, especially bilastine, levocetirizine, and rupatadine, which are one of the concerns for conducting the present study in AR.

The demographic results in this comparative study show no significant difference, reflecting the homogeneity of study patients in three groups. A comparison of these three drugs concerning clinical efficacy was made based on the effects of TNSS and AEC. The efficacy of the drugs assessed clinically revealed improvement symptomatically within the groups at the end of the treatment, whereas the mean change in TNSS was not statistically significant among the groups. The effect of bilastine, levocetirizine, and rupatadine on AEC was also not significant $(\mathrm{p}>0.05)$.

All three drugs were well tolerated. Reported adverse effects were mild and expected, lasted only for a few days, and did not require intervention. Serious or new adverse events were not reported. The sample size and duration of the study are small, and the study is open label due to the non-availability of funds. Further studies are required to consider points such as a change in the study population, seasonal variation, sample size, and duration of the study.

\section{CONCLUSION}

The three drugs bilastine, levocetirizine, and rupatadine were found to have more or less similar levels of efficacy in controlling the symptoms of AR. The mean change in TNSS was not significant among the three groups. The three drugs had no significant difference in the reduction of AEC levels. Further studies are required in larger sample size and blinding could be considered which can reproduce beneficial outcomes.

\section{ACKNOWLEDGMENT}

The authors thank Dr. T. Chakradhar, Professor and Head, Department of Pharmacology, for his advice. We would like to extend our thanks to the Department of ENT for helping us with this study. The authors thank the scholars whose publications are mentioned and listed in the manuscript's references.

\section{AUTHORS' CONTRIBUTIONS}

Dr. Veena, Dr. Monica, and Dr. Manoj helped in preparing the manuscript, Dr. Sharone Grace wrote the manuscript, Dr. Syed Arshadduddin, and Dr. Bhuvaneswari reviewed the manuscript.

\section{CONFLICTS OF INTEREST}

There are no conflicts of interest.

\section{FUNDING SOURCES}

None.

\section{REFERENCES}

1. Douglass JA, O'Hehir RE. 1. Diagnosis, treatment and prevention of allergic disease: The basics. Med J Aust 2006;185:228-33. 
2. Igea JM. The history of the idea of allergy. Allergy 2013;68:966-73.

3. Chandrika D. Allergic rhinitis in India: An overview. Int J Otorhinolaryngol Head Neck Surg 2016;3:1-6.

4. Wallace DV, Dykewicz MS, Bernstein DI, Blessing-Moore J, Cox L, Khan DA, et al. The diagnosis and management of rhinitis: An updated practice parameter. J Allergy Clin Immunol 2008;122 Suppl 2:S1-84.

5. Emeryk A, Emeryk-Maksymiuk J, Janeczek K. New guidelines for the treatment of seasonal allergic rhinitis. Postepy Dermatol Alergol 2019;36:255-60.

6. Patel GB, Kern RC, Bernstein JA, Hae-Sim P, Peters AT. Current and future treatments of rhinitis and sinusitis. J Allergy Clin Immunol Pract 2020;8:1522-31.

7. Bousquet J, Ansótegui I, Canonica GW, Zuberbier T, Baena-Cagnani CE, Bachert $\mathrm{C}$, et al. Establishing the place in therapy of bilastine in the treatment of allergic rhinitis according to ARIA: Evidence review. Curr Med Res Opin 2012;28:131-9.

8. Nettis E, Calogiuri GF, Di Leo E, Cardinale F, Macchia L, Ferrannini A, et al. Once daily levocetirizine for the treatment of allergic rhinitis and chronic idiopathic urticaria. J Asthma Allergy 2008;2:17-23.

9. Metz M, Maurer M. Rupatadine for the treatment of allergic rhinitis and urticaria. Expert Rev Clin Immunol 2011;7:15-20.

10. Ellis AK, Soliman M, Steacy L, Boulay MĖ, Boulet LP, Keith PK, et al. The allergic rhinitis-clinical investigator collaborative (ARCIC): Nasal allergen challenge protocol optimization for studying AR pathophysiology and evaluating novel therapies. Allergy Asthma Clin Immunol 2015;11:16.

11. Pawankar R, Canonica GW, Holgate ST, Lockey RF, Blaiss MS. World Allergy Organization (WAO) White Book on Allergy: Update 2013. Milwaukee, USA: World Allergy Organization; 2013. p. 11-3, 27-31, 60-3.
12. Paśko $\mathrm{P}$, Rodacki $\mathrm{T}$, Domagała-Rodacka R, Palimonka $\mathrm{K}$, Marcinkowska M, Owczarek D. Second generation H1-antihistamines interaction with food and alcohol-a systematic review. Biomed Pharmacother 2017;93:27-39.

13. Maiti R, Rahman J, Jaida J, Allala U, Palani A. Rupatadine and levocetirizine for seasonal allergic rhinitis: A comparative study of efficacy and safety. Arch Otolaryngol Head Neck Surg 2010;136:796800 .

14. Valero A, Izquierdo I, Kowalski ML, Scadding GK, Bousquet J, Mullol J. Higher efficacy of rupatadine $20 \mathrm{mg}$ and $10 \mathrm{mg}$ versus placebo in patients with perennial allergic rhinitis: A pooled responder analysis. Allergy Asthma Clin Immunol 2020;16:29.

15. Kuna P, Bachert C, Nowacki Z, van Cauwenberge P, Agache I, Fouquert L, et al. Efficacy and safety of bilastine $20 \mathrm{mg}$ compared with cetirizine $10 \mathrm{mg}$ and placebo for the symptomatic treatment of seasonal allergic rhinitis: A randomized, double-blind, parallel-group study. Clin Exp Allergy 2009;39:1338-47.

16. Okubo K, Gotoh M, Asako M, Nomura Y, Togawa M, Saito A, et al. Efficacy and safety of bilastine in Japanese patients with perennial allergic rhinitis: A multicenter, randomized, double-blind, placebocontrolled, parallel-group phase III study. Allergol Int 2017;66:97-105.

17. Potter PC, Paediatric Levocetirizine Study Group. Efficacy and safety of levocetirizine on symptoms and health-related quality of life of children with perennial allergic rhinitis: A double-blind, placebocontrolled randomized clinical trial. Ann Allergy Asthma Immunol 2005;95:175-80.

18. Bachert C, Kuna P, Sanquer F, Ivan P, Dimitrov V, Gorina MM, et al. Comparison of the efficacy and safety of bilastine $20 \mathrm{mg}$ vs desloratadine $5 \mathrm{mg}$ in seasonal allergic rhinitis patients. Allergy 2009;64:158-65. 